\title{
Vacunas para COVID-19: Estado actual y perspectivas para su desarrollo
}

\author{
COVID-19 vaccines: current status and perspectives for its development
}

Hernandez-Rojas Edith C ${ }^{1}$, Almonacid Urrego Isabel C ${ }^{2}$, Rocha Chamorro Andrea Catalina ${ }^{3}$, Salcedo Pretelt Irlena ${ }^{4}$

\section{Resumen}

La pandemia por SARS-CoV-2 evidencia la importancia del trabajo conjunto para el desarrollo de vacunas contra el virus, estas incluyen virus completos, subunidades, vacunas atenuadas, vectores virales y ácidos nucleicos, la mayoría de propuestas están basadas en subunidades proteicas. De los más de 115 candidatos reportados hasta abril, 73 se encuentran en estudios preclínicos, a junio la opción más avanzada se ubica en fase II/ II, una en fase II, dos en fase I/II y cuatro en fase I. Los candidatos más avanzados son AZD1222 (AstraZeneca) basada en adenovirus recombinante para la proteína S (fase II/III); PiCoVacc (Sinovac Biotech) basada en virus inactivado (fase I/II); mientras que mRNA1273 (Moderna) basada en ARNm para la proteína S, INO-4800 (Inovio Pharmaceticals) basada en DNA plasmídico para proteína S, Ad5-nCoV (Cansino Biologicals) basada en adenovirus tipo 5 expresando la proteína S, LV-SMENP-DC basada en células dendríticas con lentivirus para dominios de proteínas virales y aAPC patógeno-específica, basada en células presentadoras de antígenos con lentivirus para dominios de proteínas virales (ambas de Shenzhen Geno-Immune Medical Institute, se encuentran en fase I).

La finalidad de este trabajo contrarreloj se dirige hacia el único objetivo de lograr un candidato a vacuna que demuestre seguridad y efectividad en el control y prevención del

\footnotetext{
1 Investigadora Grupo EZCA- Programa de Bacteriología, Facultad de Ciencias de la Salud, Universidad Colegio Mayor de Cundinamarca. Docente, investigadora grupo INSAFUSM - Programa de Odontología, Facultad de Ciencias de la Salud, Fundación Universitaria San Martín. Miembro Asociación Científica Latina (Ascila).

ORCID: https://orcid.org/0000-0002-2874-068X

2 Investigadora Grupo EZCA- Programa de Bacteriología, Facultad de Ciencias de la Salud, Universidad Colegio Mayor de Cundinamarca. Patóloga Hospital Central de la Policía.

ORCID: https://orcid.org/0000-0002-0218-9367

3 Estudiante Semillero grupo ECZA- Programa de Bacteriología, Facultad de Ciencias de la Salud, Universidad Colegio Mayor de Cundinamarca. Bacterióloga y laboratorista clínica Universidad Colegio Mayor de Cundinamarca.

ORCID: https://orcid.org/0000-0001-8892-706X

4 Investigadora Grupo EZCA- Programa de Bacteriología, Facultad de Ciencias de la Salud, Universidad Colegio Mayor de Cundinamarca. Profesional especializado del equipo de la Subdirección de Gestión y Evaluación de Políticas en Salud Pública, Secretaría Distrital de Salud de Bogotá.

ORCID: https://orcid.org/0000-0002-9864-5426
} 
virus sorpresivo que dejó al descubierto que no hay enemigo pequeño o que mientras más pequeño más peligroso, pues el causante de COVID-19 no solo atacó la salud humana sino la economía del planeta y las costumbres y actividades rutinarias que desarrollaba la humanidad.

Palabras claves: COVID-19, vacunación, profilaxis, vontrol COVID-19, epidemia, coronavirus de Wuhan.

\section{Abstract}

The SARS-CoV-2 pandemic shows the importance of joint work for the development of vaccines against the virus, these include complete viruses, subunits, attenuated vaccines, viral vectors and nucleic acids, most of the proposals are based on protein subunits. Of the more than 115 candidates reported until April, 73 are in preclinical studies, as of June the most advanced option is in phase II / II, one in phase II, two in phase I / II and four in phase I. The candidates more advanced are AZD1222 (AstraZeneca) based on recombinant adenovirus for protein S (phase II / III); PiCoVacc (Sinovac Biotech) based on inactivated virus (Phase I / II); while mRNA-1273 (Modern) based on mRNA for protein S, INO4800 (Inovio Pharmaceticals) based on plasmid DNA for protein S, Ad5-nCoV (Cansino Biologicals) based on adenovirus type 5 expressing protein S, LV- SMENP-DC is based on dendritic cells with lentiviruses for viral protein domains and pathogen-specified aAPC, based on antigen-presenting cells with lentiviruses for viral protein domains (Shenzhen Institute of Genoimmune Medicine, are in phase I).

The purpose of this work against the clock is directed towards the sole objective of achieving a vaccine candidate who demonstrates safety and determination in the control and prevention of the surprising virus that revealed that there is no small enemy or that the smaller the more dangerous, because the cause of COVID-19 not only attacked human health but the economy of the planet and the customs and routine activities that humanity develops.

Keywords: COVID-19, Vaccines, SARS-CoV2, COVID-19 Control, Pandemic, Wuhan Coronavirus. 


\section{Introducción}

En pandemia la carrera contra el tiempo es vital en aras de conseguir una vacuna eficaz, situación ratificada frente a la COVID-19; un gran aporte en la reducción de tiempo de consecución de la posible vacuna fue conocer la secuencia genómica del virus(1), así a tan solo un par de meses de su publicación más de 50 candidatos a vacunas contra el virus se indicaron en desarrollo (2).
Las vacunas propuestas para SARS-CoV-2 se basan en tecnologías como ácidos nucleicos (DNA y RNA), subunidades proteicas recombinantes, vectores virales, virus inactivados y partículas similares a virus (Figura 1), propuestas que tienen como principal blanco la proteína $S$ involucrada en el ingreso del virus a células epiteliales $(2,3)$.

Figura 1. Candidatos a vacuna según plataforma de desarrollo. Se evidencia un mayor número de propuestas del tipo subunidades proteicas y el menor número en los candidatos basados en ácidos nucleicos. Modificado de (4).

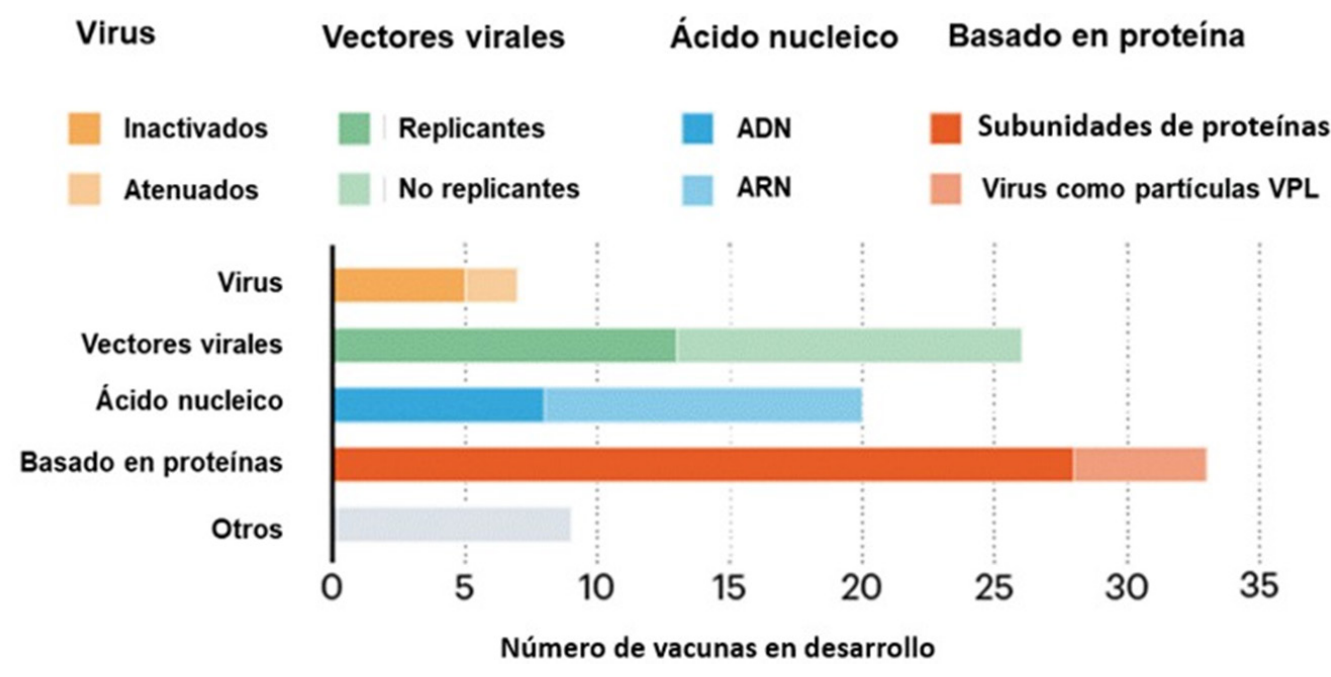

Fuente: Autores.

\section{Vacunas de ácido nucleicos}

Las de tipo ADN son plásmidos que contienen secuencias que codifican antígenos virales. Al administrar estas vacunas las proteínas virales se producen a expensas de la síntesis realizada por células del huésped; las vacunas de tipo ARNm funcionan similar, pero inician un paso antes de la síntesis proteica, simulando el proceso infeccioso de producción y procesamiento de proteínas virales, conllevando a activación de Linfocitos T CD4+, CD8+ y producción de anticuerpos $(3,4)$.

Respecto a estas vacunas, cerca de 10 se encuentran en desarrollo, incluyendo la de US Inovio y su vacuna INO-4800 en 
inicio de estudios clínicos (5) y Moderna, BioNTech/Pfizer con ARNm-1273 de Estados Unidos en colaboración con el Instituto Nacional de Alergias y Enfermedades Infecciosas (Niaid), es la primera en la cual los estudios humanos y animales se realizan simultáneamente (6). Este tipo de vacunas pueden diseñarse y producirse rápidamente, adicionalmente las de ARNm se consideran estables, rentables y de fácil producción. No obstante, aún no se logra la producción y aplicación de estas para uso humano por lo que no son claros los mecanismos de inmunidad ni la duración de esta (7).

\section{Vacunas de virus}

Utilizan directamente SARS-CoV-2 en "forma debilitada (atenuada) o inactivada; se han desarrollado algunos mutantes atenuados eliminando el gen para la proteína E del virus, anulando su virulencia y generando anticuerpos neutralizantes en animales inmunizados, sugiriendo que podría ser el primer paso en el desarrollo de una vacuna atenuada del virus» (8).

Al menos siete equipos están desarrollando este tipo de vacuna, entre ellos Chinese $\mathrm{Si}$ novac Biotech (Beijing), quienes prueban en humanos una versión inactivada del virus SARS-CoV-2 $(4,9)$. Solo un candidato a vacuna utilizando un virus atenuado vivo tradicional se encuentra en desarrollo por Codagenix junto con el Instituto del Suero de la India (10).

\section{Vacunas de vectores virales}

Consisten en virus modificados genéticamente expresando antígenos de otros microorganismos (7). Un aspecto negativo de estas es la necesidad de cultivo que dificulta su mantenimiento y alarga su producción a gran escala (4).

Se encuentran en desarrollo 15 vacunas de este tipo para la expresión principalmente del antígeno $S$, dentro de estas se halla la propuesta por la Universidad de Oxford denominada vacuna vectorial ChAdOx1 nCoV-19 que emplea adenovirus de chimpancé, utilizado anteriormente para una vacuna de MERS que alcanzo la fase 1 (11), así mismo CanSino Biologics (China) está desarrollando Ad5-nCoV empleando adenovirus y se encuentra en ensayos clínicos (12).

\section{Vacunas con proteínas}

Este tipo de vacunas están basadas en subunidades proteicas, péptidos sintéticos o proteínas recombinantes ya sea de forma completa o subunidades del antígeno deseado, haciéndolas así más seguras por incluir los antígenos puros (2). Una desventaja es que inducen respuesta inmune por anticuerpos sin participación de Linfocitos T CD8+, fundamentales en inmunidad viral y requieren en su composición un adyuvante para obtener respuesta inmune adecuada (13). 
La Universidad de Queensland (Australia) desarrolló un candidato con estudios preclínicos en desarrollo, basada en que las subunidades libres del trímero de la proteína $S$ son inestables, para lo cual ideó la técnica de abrazadera molecular que estabiliza los trímeros, esperando que los anticuerpos producidos sean específicos para esta forma bloqueando la unión virus-célula blanco (13); Clover Biopharmaceuticals (China) está desarrollando una posible vacuna basada en el mismo principio (14), estos dos grupos se asociaron con Glaxo Smith Kline, accediendo a su adyuvante pandémico para perfeccionar sus candidatos vacunales. Igualmente, Novavax Inc (Estados Unidos) desarrolla un candidato basado en proteínas de superficie del virus dispuestas en nanoparticulas combinadas con adyuvante Matrix-M a base de saponina (15).

Existen muchos y múltiples estudios de vacunas, para abril del 2020 se tenían cerca de 115 candidatos, de estas 78 confirmadas como activas, 73 se encuentran en estudios preclínicos o exploratorios, mientras que a junio se reportaba que la más avanzada está en fase II/III, una en fase II, dos en fase I/II y cuatro en fase I (16). Dentro de las más avanzados se encuentra AZD1222 de AstraZeneca (Reino Unido) licenciada por la Universidad de Oxford, con inyección monetaria de Investigación Biomédica Avanzada de EE. UU., basada en adenovirus recombinante codificante para proteína $S$; se demostró que una dosis única protegía ratones y macacos Rhesus, actualmente comenzó la fase II/II con más de 10000 voluntarios.

De otro lado, Sinovac Biotech (Beijing) ha indicado que su vacuna PiCoVacc, basada en virus inactivado purificado, tras 3 dosis evidenció en macacos protección completa contra el virus, se encuentra en fase I/II (7). Por otra parte, los candidatos a vacuna de Moderna (mRNA-1273), Inovio (INO4800), Cansino Biologicals (Ad5-nCoV), Shenzhen Geno-Immune Medical Institute (LV-SMENP-DC y aAPC patógeno-específica) se encuentran actualmente en fases clínicas de desarrollo (Tabla 1) (16). 
Tabla 1. Candidatos a vacuna para SARS-CoV-2 en fase clínica.

\begin{tabular}{|c|c|c|c|}
\hline CARACTERÍSTICAS & CANDIDATO & DESARROLLADOR & ESTADO \\
\hline mRNA-1273 & $\begin{array}{l}\text { Vacuna de mRNA codifiante para } \\
\text { proteína } S \text { encapsulado en LNP }\end{array}$ & Moderna. NIAID & Fase 1 (NCT04283461) \\
\hline Ad5-nCov & $\begin{array}{l}\text { Vector Adenovirus tipo } 5 \\
\text { expresando proteína } \mathrm{S}\end{array}$ & $\begin{array}{l}\text { Cansino Biologicals Instituto de } \\
\text { Biotecnología de Beijing }\end{array}$ & Fase 11 (NCT04313127) \\
\hline INO-4800 & $\begin{array}{l}\text { DNA plasmidico codificado } \\
\text { proteína } S \text { liberado por } \\
\text { electroporación }\end{array}$ & Inovio Pharmaceuticals & Fase 11 (NCT04336410) \\
\hline LV-SMENP-DC & $\begin{array}{l}\text { DCs modificadas con vector } \\
\text { lentiviral expresando minigen } \\
\text { sintético basado en dominios de } \\
\text { proteínas virales seleccionadas; } \\
\text { administrada con CTL específicas }\end{array}$ & $\begin{array}{l}\text { Shenzhen Geno-Inmune Medical } \\
\text { Institute }\end{array}$ & Fase 1 (NCT04276896) \\
\hline aAPC Patógeno-Específica & $\begin{array}{l}\text { aAPC modificadas con vector } \\
\text { lentiviral expresando minigen } \\
\text { sintético basado en dominios de } \\
\text { proteínas virales seleccionadas }\end{array}$ & $\begin{array}{l}\text { Shenzhen Geno-Inmune Medical } \\
\text { Institute }\end{array}$ & Fase 1 (NCT04299724) \\
\hline AZD1222 (ChAdOx1nCoV-19) & $\begin{array}{c}\text { Vector Adenovirus Recombinante } \\
\text { de chimpancé expresando } \\
\text { proteína S }\end{array}$ & $\begin{array}{c}\text { AztraZeneca, Universidad de } \\
\text { Oxford }\end{array}$ & Fase II/III \\
\hline $\begin{array}{l}\text { BNT162a1 BNT162b1 } \\
\text { BNT162b2 } \\
\text { BNT162c1 }\end{array}$ & $\begin{array}{l}\text { Vacunas basadas en mRNA } \\
\text { expresando Proteína S o su } \\
\text { dominio de unión al receptor }\end{array}$ & $\begin{array}{l}\text { BionTech (Mainz-Alemania), } \\
\text { Pfizer, Fosun Pharma (Shangai) }\end{array}$ & Fase $1 / 2$ \\
\hline NVX-CoV2373 & $\begin{array}{l}\text { Sub-unidad recombinante de } \\
\text { proteína } \mathrm{M} \text { con adyuvante } \\
\text { y proteína } S\end{array}$ & Novavax & Fase $1 / 2$ \\
\hline
\end{tabular}

aAPC: célula Presentadora de antígeno artificial; CTL: Linfocito T Citotóxico; DC: célula dendrítica; LNP: nanopartícula lipídica; proteína S: proteína Spike de SARS-CoV-2, modificado de $(16,17)$.

\section{Conclusión}

En definitiva, lo más importante en esta carrera contra el tiempo es lograr un candidato a vacuna que demuestre en ensayos clínicos gran seguridad y eficacia. Así como la participación de importantes actores: academia, sectores público, privado e industria, estos, unidos, que entiendan la necesidad de lograr el objetivo, permitan con sus esfuerzos mancomunados garantizar la producción, suministro y cubrimiento de la demanda de la vacuna generada, todo con el único fin de controlar la pandemia que tomó a todos por sorpresa y que tantos y tan grandes efectos negativos ha generado en la población mundial. 


\section{Referencias}

1. GenBank. Severe acute respiratory syndrome coronavirus 2 isolate Wuhan-Hu-1, complete genome. [Internet]. [Consultado el 11 feb 2020]. Disponible en: http://www.ncbi.nlm.nih.gov/nuccore/ MN908947.3.

2. World Health Organization (WHO). DRAFT landscape of COVID-19 candidate vaccines-20 April 2020. [Internet]. Disponible en: https:// www.who.int/blueprint/priority-diseases/key-action/novel-coronavirus-landscape-ncov.pdf?ua $=1$.

3. Lawrence C, Mascola J, Fauci A, Collins F. A strategic approach to COVID-19 vaccine R\&D. Science [Internet]. 2020. [Consultado 29 de may 2020]; 368 ISSUE 6494. Disponible en: DOI: https:// doi.org/10.1126/science.abc5312

4. Ewen C. The race for coronavirus vaccines: a graphical guide. Nature [Internet]. 2020 [Consultado Apr 2020]; 580(7805):576-577. Disponible en: DOI: https://doi.org/10.1038/d41586-02001221-y.

5. Inovio. Inovio accelerates timeline for COVID-19 DNA vaccine INO-4800 [pressmeddelande]. 3 mar 2020 [citerat 19 mar 2020]. https://www.prnewswire.com/news-releases/inovio-accelerates-timeline-for-covid-19-dna-vaccine-ino-4800-301015031.html.

6. ClinicalTrials.gov. Safety and immunogenicity study of 2019-nCoV vaccine (mRNA-1273) to prevent SARS-CoV-2 infection [Internet]. [Consultado 29 Mar 2020]. NCT04283461. Disponible en: https://clinicaltrials.gov/ct2/show/ NCT04283461.

7. Susannah L. At least 68 vaccine candidates under development. Lakartidningen [Internet] 2020 [Consultado 6 Apr 2020];117:F3MZ.

8. Lamirande EW, DeDiego ML, Roberts A, Jackson JP, Alvarez E, Sheahan T, et al. A live attenuated severe acute respiratory syndrome coronavirus is immunogenic and efficacious in golden Syrian hamsters. J. Virol. 2008;82(15):7721-7724.

9. Lin JT, Zhang JS, Su N, et al. Safety and immunogenicity from a phase I trial of inactivated severe acute respiratory syndrome coronavirus vaccine. Antivir Ther. 2007;12(7):1107-13.

10. Codagenix, Inc. Codagenix and Serum Institute of India initiate co-development of a scalable, live-attenuated vaccine against the 2019 novel coronavirus, COVID-19 [Internet]. [Consultado 19 Mar 2020]. Disponible en: https://www.prnewswire.com/news-releases/codagenix-and-serum-institute-of-india-initiate-co-development-of-a-scalable-live-attenuated-vaccine-against-the-2019-novel-coronavirus-covid-19-301004654.html.

11. ClinicalTrials.gov. Safety and immunogenicity of a candidate MERS-CoV vaccine (MERS001) [Internet]. [Consultado 20 mar 2020]. NCT03399578. Disponible en: https://clinicaltrials.gov/ct2/show/ NCT03399578.

12. Chinese Clinical Trial Register (ChiCTR). A phase I clinical trial for recombinant novel coronavirus (2019-COV) vaccine (adenoviral vector). [Internet]. [Consultado 29 Mar 2020]. ChiCTR2000030906. Disponible en: http://www.chictr.org.cn/showprojen.aspx?proj=51154.

13. Chappell K, Watterson D, Young P. Rapid response pipeline for stabilized subunit vaccines. Vaccine Technology VII [Internet]. 2018 [consultado 20 Jun 2018]. Disponible en: https://dc.engconfintl. org/vt_vii/111.

14. Clover Biopharmaceuticals. Comunicado de prensa: Clover successfully produced 2019-nCoV subunit vaccine candidate and detected cross-reacting antibodies from sera of multiple infected patients [Internet]. 2020. [Consultado 19 Mar 2020]. Disponible en: http://www.cloverbiopharma.com/ index.php? $m=$ content \&c=index \&a=show \&cati$\mathrm{d}=11 \& \mathrm{id}=41$.

15. Novavax. Comunicado de prensa: Novavax advances development of novel COVID-19 vaccine [Internet]. 2020. [Consultado 19 Mar 2020]. Dis- 
ponible en: http://ir.novavax.com/news-releases/ news-release-details/novavax-advances-development-novel-covid-19-vaccine.

16. Tung TL, Zacharias A, Arun K, Gómez R, et al. The COVID-19 vaccine development landscape. Nat Rev Drug Discov. 2020:19(5)305-306.

17. Cormac S. Questions remain following first COVID-19 vaccine results. Nat Biotechnol [Internet] 2020. DOI: https://doi.org/10.1038/D41587020-00015. 